\title{
Morfofisiologia do Dossel de Panicum maximum cv. Mombaça sob Lotação Intermitente com Três Períodos de Descanso ${ }^{1}$
}

\section{Magno José Duarte Cândido ${ }^{2}$, Carlos Augusto Miranda Gomide ${ }^{3}$, Emerson Alexandrino ${ }^{4}$, José Alberto Gomide ${ }^{5}$, Walter Esfrain Pereira ${ }^{6}$}

\begin{abstract}
RESUMO - Avaliaram-se o fluxo de biomassa e as características estruturais do dossel de Panicum maximum cv. Mombaça sob pastejo de lotação intermitente, com os períodos de descanso (PD) definidos em função do tempo necessário para a expansão de 2,5; 3,5 e 4,5 novas folhas por perfilho (tratamentos). A pastagem foi dividida em cinco ou seis piquetes, conforme o tratamento, caracterizando o delineamento de casualização completa. Utilizaram-se cinco novilhos Holandês/Zebu por tratamento, que pastejaram durante seis dias em cada um dos piquetes correspondentes. Animais de equilíbrio foram adicionados, quando necessário, para garantir índice de área foliar residual próximo de 2,0, ao final do 6ํㅜ dia de pastejo. Durante os PDs de três ciclos de pastejo, estimaram-se as taxas de aparecimento, alongamento e senescência foliares (TApF, TAlFe TSF, respectivamente), a taxa de alongamento das hastes (TAlH) e a taxa de acúmulo de forragem (TAF). No início e final de cada PD, estimaram-se: altura do dossel, massa seca de forragem verde (MSFV) e relação folha/colmo. Logo após cada período de pastejo, estimou-se a densidade populacional de perfilhos (DPP). As características mais afetadas pelos PDs foram TAlH e relação folha/colmo. OPD de 2,5 folhas foi o único a exercer algum controle sobre o alongamento das hastes. Observou-se ainda forte plasticidade do dossel em resposta aos PDs. A TAlF (7,6 cm/perf x dia) e a DPP (350 perf $\left./ \mathrm{m}^{2}\right)$ nos piquetes sob menor PD e a TAlH $(0,29 \mathrm{~cm} /$ perf x dia $)$ naqueles sob maior PD constituíram-se componentes importantes da produção. O prolongamento do PD acarretou maior altura e maior MSFV por ciclo de pastejo, porém com proporção crescente de colmos, acarretando acentuada redução na relação folha/colmo.
\end{abstract}

Palavras-chave: relação folha/colmo, taxa de alongamento foliar, taxa de alongamento das hastes, taxa de senescência foliar

\section{Morphophysiology of Panicum maximum cv. Mombaça Canopy under Intermittent Stocking Grazing of Three Rest Periods}

\begin{abstract}
The tissue flow and structural traits of Panicum maximum cv. Mombaça canopy were evaluated under intermittent stocking, with rest period (RP) defined in terms of the time required for the expansion of $2.5 ; 3.5$ and 4.5 new leaves per tiller. The pasture treatment was divided into five or six paddocks (replicates) per treatment, observing a completely randomized design. One group of five Holstein-Zebu crossbred steers, as testers, grazed the paddocks of the respective treatment during six days. Put and taken steers were used, when necessary, to obtain a residual leaf area index (LAI) of about 2.0, by the end of the $6^{\text {th }}$ grazing day. During the RPs of three grazing cycles, leaf elongation rate (LER), leaf senescence rate (LSR), culm elongation rate (CER) and net herbage accumulation rate (NHAR) were estimated. By the beginning and end of each RP, the following structural variables were estimated: canopy height, green herbage dry matter (GHDM) and leaf/culm ratio. Tiller population density (TPD) was assessed after each grazing period. The variables CER and leaf/culm ratio were markedly affected by the RP. Only the short 2.5 leaves RP exerted some control upon culm elongation. Marked canopy plasticity was observed in response to RPs. LER $\left(7.6 \mathrm{~cm} /\right.$ tiller $\mathrm{x}$ day) and TPD (350 tillers $\left./ \mathrm{m}^{2}\right)$ were the determinant growth components in 2.5 leaves canopy, while CER $(0.29 \mathrm{~cm} / \mathrm{tiller} \mathrm{x}$ day) was the important growth component in the 4.5 leaves canopy regrowth. The longer the RP, the higher the canopy height and the GHDM, due to increasing contribution of culm fraction, which brought about marked reduction in leaf/culm ratio.
\end{abstract}

Key Words: culm elongation rate, leaf elongation rate, leaf/culm ratio, leaf senescence rate

\section{Introdução}

Juntamente com os fatores de ambiente (temperatura, luz, $\mathrm{CO}_{2}$, água, nitrogênio etc), o manejo é fator determinante das características morfogênicas e estruturais da pastagem (Lemaire \& Chapman, 1996).
Entre os sistemas de manejo da pastagem, destaca-se o pastejo de lotação intermitente, caracterizado pela duração dos períodos de descanso e pastejo, perfazendo os sucessivos ciclos de pastejo dos diferentes piquetes em que a pastagem é dividida.

\footnotetext{
1 Parte da tese de doutorado do primeiro autor; Bolsista do CNPq; Pesquisa Financiada pela FAPEMIG;

2 Professor Adjunto, Departamento de Zootecnia, Universidade Federal do Ceará, Av. Mister Hull, 2977, Campus Universitário do Picí, FortalezaCE, 60970-355, TEL: (85)4008-9711, FAX: (85)4008-9701 (mjdcandido@gmail.com).

3 Pesquisador da Embrapa/CNPGL (cagomide@cpatc.embrapa.br).

${ }^{4}$ Professor Adjunto de Nutrição e Pastagem do Departamento de Agronomia, Universidade Federal de Rondônia, Campus de Rolim de Moura, Avenida Norte Sul, 7300, Bairro Nova Morada, Rolim de Moura, Rondônia, CEP: 78987-000.

5 Pesquisador bolsista do CNPq. Universidade Fedral de Viçosa, Av. P.H. Rolfs, s/n, Viçosa-MG, CEP: 36571-000.

${ }^{6}$ Prof. Adjunto de Estatística Experimental, Departamento de Ciências Fundamentais e Sociais, Centro de Ciências Agrárias, Universidade Federal da Paraíba - UFPB - Campus III, Areia, PB, 58397-000.
} 
A correta definição do período de descanso contribui para o sucesso desse sistema de manejo. Períodos de descanso de adequada duração propiciam a restauração da área foliar, a intercepção da luz, a produção de forragem, a restauração das reservas orgânicas, mas períodos de descanso muito longos comprometem o valor nutritivo da forragem, a estrutura do dossel forrageiro, assim como o consumo de forragem e o rendimento animal na pastagem.

Portanto, a criteriosa definição do período de descanso reveste-se de grande importância. A literatura relata diversos experimentos sobre critérios pertinentes ao intervalo de desfolhação das forrageiras ou à definiçãa do período de descanso, como restauração das reservas orgânicas (Fulkerson \& Donaghy, 2001), área foliar (Brougham, 1956), intercepção da radiação luminosa (Korte et al.,1982; Parsons et al., 1983), taxa média de acúmulo de massa de forragem (Robson,1973; Parsons \& Penning, 1988) e, mais recentemente, número constante de folhas verdes por perfilho (Grant et al.,1988; Fulkerson \& Donaghy, 2001). Este último critério, fundamentado na morfogênese da forrageira, visa prevenir as perdas de biomassa por senescência e morte de folhas e perfilhos, de modo a otimizar a eficiência de utilização da forragem produzida.

Após pastejo, a dinâmica de recuperação do dossel forrageiro caracteriza-se pelo fluxo de biomassa, envolvendo processos de formação, crescimento, desenvolvimento e senescência de novas folhas e perfilhos, estimados pelas respectivas taxas.

No início da recuperação do dossel, o número de novas folhas verdes eleva-se até que as taxas de aparecimento e de senescência foliares se igualem, tornando o número de folhas verdes por perfilho constante, conforme a espécie forrageira: 10,6 para Pennisetum purpureum cv. Napier (Pedreira \& Boin, 1969); três, para o azevém (Robson, 1973); nove, para o capim-Tifton 85 (Oliveira et al., 2000) etc. De estudo com capim-mombaça (Panicum maximum Jacq.), em vasos em casa de vegetação, Gomide \& Gomide (2000) estimaram em 10 dias o intervalo de aparecimento de folhas, em 36 dias a vida útil das folhas e, conseqüentemente, em torno de 3,5 o número de folhas verdes por perfilho.

Neste estudo, objetivou-se investigar o efeito de diferentes períodos de descanso de piquetes de capim-mombaça, definidos em função do número de novas folhas expandidas por perfilho, sobre o fluxo de biomassa (taxas de aparecimento, de alongamento e de senescência de folhas e de alongamento das has- tes), as características estruturais do dossel (população de perfilhos, altura e relação folha/colmo) a produção e o acúmulo de biomassa na pastagem.

\section{Material e Métodos}

$\mathrm{Na}$ Central de Experimentação, Pesquisa e Extensão do Triângulo Mineiro (CEPET/UFV), foi conduzido um estudo da morfogênese e estrutura do dossel de Panicum maximum cv. Mombaça sob pastejo intermitente e taxa de lotação variável, com três períodos de descanso. A CEPET situa-se a $18^{\circ} 41^{\prime}$ de latitude sul e 49034' de longitude oeste e as condições climáticas durante o período experimental de 21 semanas (novembro de 2000 a março de 2001), registradas em

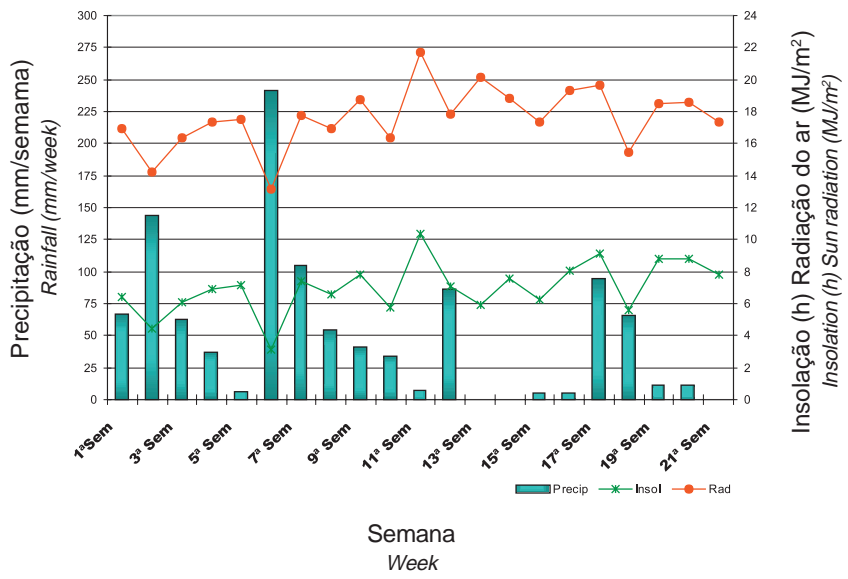

Figura 1 - Regime pluviométrico ( ( ), de radiação solar (_- ) e de insolação (__ ) durante o período experimental.

Figure 1 - Rainfall ( $\mathbf{0}$ ), solar radiation (-) and insolation (_- ) regimes in the experimental period.

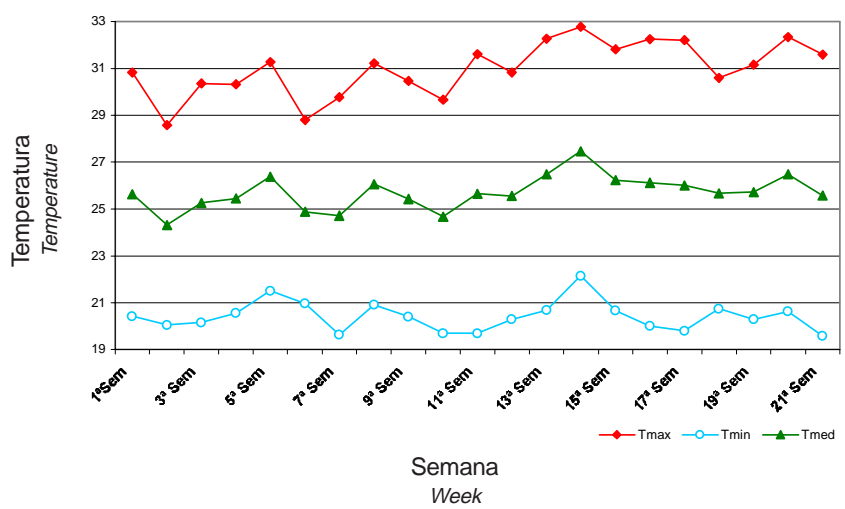

Figura 2 - Flutuação semanal nas temperaturas máxima $\left(\bullet_{-}\right)$, média $(\rightarrow)$ e mínima $\left(-_{-}\right)$do ar durante o período experimental.

Figure 2 - Weekly means of maximum (--), medium (-) and minimum (- $\left.{ }_{-}\right)$air temperatures in the experimental period. 
uma estação meteorológica instalada nas proximidades da área experimental, encontram-se nas Figuras 1 e 2.

A área experimental, de seis hectares, foi preparada e semeada após calagem (2 t/ha) em 1998, adubada com fosfato de Araxá (1 t/ha) e manejada sob lotação intermitente na estação de crescimento 1999-2000.

Três tratamentos (períodos de descanso), foram definidos em função do tempo necessário para a expansão de 2,5; 3,5 e 4,5 novas folhas por perfilho, após período de pastejo de seis dias. Como o capimmombaça mantém, em média, 3,5 folhas verdes por perfilho (Gomide \& Gomide, 2000), assumiu-se que o mais longo período de descanso (4,5 novas folhas) resulte na senescência e morte da primeira folha expandida.

A área experimental foi dividida em seis piquetes por tratamento, dos dois mais longos períodos de descanso, e cinco piquetes sob a freqüência de desfolhação de 2,5 novas folhas, cujas áreas eram inversamente proporcionais à duração dos períodos de descanso, perfazendo, portanto, cinco piquetes de $2.350 \mathrm{~m}^{2}$ e seis de 1.600 e $1.200 \mathrm{~m}^{2}$, destinados aos tratamentos 2,5; 3,5 e 4,5 folhas, respectivamente. A área variável dos piquetes por tratamento foi adotada como primeira aproximação para se conseguir em todos eles a mesma biomassa de forragem à entrada dos animais em cada piquete. O restante dos 6 ha foi utilizado como área de reserva.

Para o condicionamento do pastejo de lotação intermitente, foi efetuada roçada mecânica da pastagem por meio de segadora condicionadora, no início do período experimental, após pastejo pelos novilhos, para o consumo do excesso da forragem existente. A roçada foi realizada de forma escalonada a $20 \mathrm{~cm}$ do solo, altura em que seriam feitas as estimativas de massa de forragem pelo método agronômico, de modo que, no dia 6 de novembro, foi roçado o primeiro piquete de cada um dos períodos de descanso preconizados (2,5; 3,5 e 4,5 folhas); no dia 12 de novembro, o segundo piquete de cada um dos períodos de descanso, e assim sucessivamente, até que o último piquete de cada sistema fosse roçado um dia antes do primeiro piquete completar o período de descanso, quando este recebeu os novilhos para o primeiro pastejo. A diferença de seis dias entre as roçadas sucessivas obedeceu ao critério de seis dias de período de pastejo estabelecido para cada piquete.

Imediatamente após a roçada, realizou-se adubação em cobertura de cada piquete, de $250 \mathrm{~kg} / \mathrm{ha}$ da mistura 20-5-20 (N-P $\left.2 \mathrm{O}_{5}-\mathrm{K}_{2} \mathrm{O}\right)$. A mesma adubação foi repetida, no início do período experimental, imediatamente após a saída dos animais do piquete. A área de reserva foi adubada com a mesma dose e periodicidade adotada para os piquetes.

Foram utilizados 15 novilhos mestiços (Holandês-Zebu) como animais de prova, além de outros como animais de equilíbrio. A cada tratamento (período de descanso), correspondeu um grupo de cinco novilhos (animais de prova), que pastejaram durante seis dias em cada piquete do respectivo tratamento, de forma sucessiva. Quando necessário, os animais permaneceram na área de reserva, após pastejo no último piquete do ciclo de seu tratamento, à espera de que o primeiro piquete pastejado apresentasse sua condição experimental para nova ocupação, novo ciclo de pastejo. Novilhos extras (animais de equilíbrio), mantidos na área de pasto de reserva, foram conduzidos aos piquetes em pastejo, quando necessário, para garantir que, ao final do último dia do período de pastejo, a vegetação apresentasse índice de área foliar (IAF) em torno de 2,0, inicialmente estimado com um Sistema de Análise do Dossel (SunScan da Delta-T Devices Ltd.), e, posteriormente, estimado visualmente.

Durante os períodos de descanso, acompanhouse o fluxo de biomassa da gramínea. A cada ciclo de pastejo, foram marcadas três touceiras em dois piquetes de cada tratamento, após a saída dos animais. Em cada ciclo, novas touceiras foram marcadas em outros dois piquetes de cada tratamento e, em cada uma, três perfilhos foram identificados aleatoriamente com anéis coloridos de fio telefônico, com fitas coloridas da mesma cor, atadas para facilitar sua localização. Nestes perfilhos, registrou-se, a cada cinco dias, o comprimento total e o da porção verde de cada uma das lâminas foliares não completamente morta a partir da sua lígula, quando já expandida, ou da lígula da folha mais recentemente expandida - em se tratando de folha emergente. O comprimento da porção senescente foi obtido pela diferença entre o comprimento total da lâmina foliar ao tempo de sua completa expansão e o comprimento da porção ainda verde, ao final do período de medição. Estimou-se, ainda, o alongamento das hastes, como a diferença das distâncias entre o solo e a lígula da folha recém-expandida por ocasião da primeira e da última leitura do período de medição.

Ao final de cada período de descanso, foram colhidos aleatoriamente, 30 perfilhos em cada piquete, que foram levados ao laboratório, separados em hastes, 
lâmina de folha expandida e lâmina de folha emergente, registrando-se o comprimento de cada. As frações foram submetidas à secagem em estufa de ventilação forçada a $65^{\circ} \mathrm{C}$, durante 72 horas, e pesadas. A partir de suas medidas e de seus pesos, foram estimados o índice de peso por unidade de comprimento de lâmina foliar emergente, oíndice de peso por unidade de comprimento de lâmina foliar adulta e outro para hastes.

Assim, foi possível determinar a taxa de acúmulo de forragem (TAF) durante os períodos de descanso a partir das taxas de alongamento (TAlF) e senescência (TSF) de lâmina foliar, da taxa de alongamento das hastes (TAlH) e da densidade populacional de perfilhos (DPP), conforme Davies (1993).

A fim de se definir o momento de entrada dos animais em cada piquete, o número de novas folhas expandidas por perfilho foi monitorado durante o período de descanso.

Ao final de cada período de descanso, anteriormente à entrada dos animais, foram feitas as seguintes avaliações nos piquetes pertinentes:

a) Altura do dossel, estimada medindo-se a altura em 30 pontos por piquete, utilizando-se uma régua graduada;

b) Colheita de biomassa total feita a $20 \mathrm{~cm}$ do solo, em duas amostras de $1 \times 1 \mathrm{~m}$ por piquete. Foram separados, em laboratório, o material vivo do material morto e, em seguida, as lâminas foliares das hastes do material vivo, que foram secos em estufa de ventilação forçada a $65^{\circ} \mathrm{C}$ e pesados. A partir dos dados obtidos, estimou-se a massa seca de lâminas foliares verdes, massa seca de colmos verdes, a relação folha/ colmo e a massa seca de forragem verde.

Ao final de cada período de pastejo, também foram feitas as seguintes avaliações em cada piquete:

a) Densidade populacional de perfilhos: estimada contando-se o número de touceiras presentes em uma área de $10 \times 10 \mathrm{~m} \mathrm{e}$, em seguida, contando-se o número de perfilhos de quatro touceiras representativas dessa mesma área;

b) Altura do dossel, estimada como descrito anteriormente;

c) Massa seca de forragem verde, conforme descrito anteriormente. No último ciclo de pastejo, também foram determinadas a relação folha/colmo e a massa seca de lâminas foliares verdes e de colmos verdes, para avaliar a condição da estrutura residual do dossel, após sucessivos ciclos de pastejo.

As estimativas morfogênicas e estruturais, efetuadas em diferentes piquetes ao longo de três ciclos sucessivos, foram submetidas à análise estatís- tica pelo procedimento GLM do pacote estatístico SAS (SAS Institute, 1999), segundo o modelo:

$$
\mathrm{Y}_{\mathrm{ijk}}=\mathrm{m}+\mathrm{T}_{\mathrm{i}}+\mathrm{C}_{\mathrm{j}}+(\mathrm{TC})_{\mathrm{ij}}+\varepsilon_{\mathrm{ijk}} \text {, }
$$

em que $\mathrm{Y}_{\mathrm{ijk}}=$ observação relativa ao $\mathrm{k} \underline{\mathrm{o}}$ piquete, no $\mathrm{j} \underline{\mathrm{o}}$ ciclo de pastejo, do io período de descanso; $\mathrm{m}=$ média da população; $\mathrm{T}_{\mathrm{i}}=$ efeito do i⿳o período de descanso; $\mathrm{i}=1,2,3$ períodos de descanso; $\mathrm{C}_{\mathrm{j}}=$ efeito do $\mathrm{j}^{\underline{0}}$ ciclo de pastejo; $\mathrm{j}=1^{\stackrel{\mathrm{o}}{ }}, 2^{\stackrel{\mathrm{o}}{ }}, 3^{\stackrel{\mathrm{o}}{ }}$, ciclo de pastejo; $(\mathrm{TC})_{\mathrm{ij}}=$ interação período de descanso x ciclo de pastejo; $\varepsilon_{\mathrm{ijk}}$ $=$ efeito aleatório relativo ao $\mathrm{k}^{\underline{\mathrm{o}}}$ piquete, no $\mathrm{j} \underline{\mathrm{o}}$ ciclo de pastejo, do $\mathrm{i}^{\mathrm{O}}$ período de descanso; $\mathrm{k}=1,2$ piquetes (unidades experimentais).

As estimativas de densidade populacional de perfilhos (DPP), oriundas de contagem, sofreram transformação raiz quadrada com o auxílio do pacote estatístico SAS (SAS, 1999).

\section{Resultados e Discussão}

\section{Características estruturais}

A altura do dossel aumentou $(\mathrm{P}<0,05)$ com a duração do período de descanso (Tabela 1). Longo período de descanso e de pastejo seletivo de folhas, propiciando o alongamento de colmo, resultaram no desenvolvimento de dossel mais alto. Esta observação corrobora os resultados de Uebele (2002) sobre os efeitos da freqüência do pastejo sobre a altura do dossel do capim-mombaça.

Igualmente, o período de descanso e os ciclos de pastejo ocasionaram variações $(\mathrm{P}<0,05)$ na densidade populacional de perfilhos (Tabela 2). Alta população de perfilhos foi observada em piquetes sob pastejos freqüentes, acentuando-se com o suceder dos ciclos de pastejo. Este resultado se atribui à alteração do espectro solar transmitido por intermédio do dossel até a superfície do solo.

Em decorrência do sombreamento mútuo das folhas, a radiação luminosa incidente sobre um dossel fechado se altera em quantidade e qualidade à medida que permeia pelo seu perfil, com redução da relação V/Ve (vermelho/vermelho extremo). Essa alteração luminosa, detectada pelo fitocromo, desencadeia uma resposta fotomorfogênica (Smith, 1982; Chory,1997), caracterizada pelo alongamento das hastes, incluindo colmo (Smith,1982) e bainhas (Davis \& Simmons,1994) e inibição do perfilhamento da gramínea (Deregibus et al., 1985; Wan \& Sosebee, 1998). 
Tabela 1 - Altura pré-pastejo $(\mathrm{cm})$ do dossel de Panicum maximum cv. Mombaça sob três períodos de descanso, ao longo de ciclos de pastejo sucessivos

Table 1 - Pre-grazing canopy height $(\mathrm{cm})$ of Panicum maximum cv. Mombaça under three rest periods over succeeding grazing cycles

\begin{tabular}{|c|c|c|c|c|}
\hline \multirow[t]{2}{*}{$\begin{array}{l}\text { Período de descanso } \\
\text { Restperiod }\end{array}$} & \multicolumn{3}{|c|}{$\begin{array}{l}\text { Ciclo de pastejo } \\
\text { Grazing cycle }\end{array}$} & \multirow[t]{2}{*}{$\begin{array}{l}\text { Média } \\
\text { Mean }\end{array}$} \\
\hline & $1^{\mathrm{o}}\left(1^{s t}\right)$ & $2^{\mathrm{o}}\left(2^{n d}\right)$ & $3^{\mathrm{o}}\left(3^{r d}\right)$ & \\
\hline $\begin{array}{l}2,5 \text { folhas } \\
2.5 \text { leaves }\end{array}$ & 77 & 68 & 63 & 69B \\
\hline $\begin{array}{l}3,5 \text { folhas } \\
3.5 \text { leaves }\end{array}$ & 93 & 93 & 101 & $96 \mathrm{AB}$ \\
\hline $\begin{array}{l}4,5 \text { folhas } \\
4.5 \text { leaves }\end{array}$ & 112 & 113 & - & $112^{\mathrm{A}}$ \\
\hline $\begin{array}{l}\text { Média } \\
\text { Mean }\end{array}$ & $94^{\mathrm{a}}$ & $80^{\mathrm{a}}$ & $82^{\mathrm{a}}$ & \\
\hline
\end{tabular}

Médias seguidas por letras distintas, maiúsculas nas colunas e minúsculas nas linhas, diferem $(P<0,05)$ pelo teste Tukey.

Means by distintct capital and lower case letters in columns and line, respectively, differ $(P<.05)$ by Tukey test.

Tabela 2 - Densidade populacional de perfilhos (perf $\left./ \mathrm{m}^{2}\right)$ em piquetes de Panicum maximum cv. Mombaça sob três períodos de descanso, ao longo de ciclos de pastejos sucessivos ${ }^{1}$

Table 2 - Tiller population density (tillers $/ \mathrm{m}^{2}$ ) in Panicum maximum cv. Mombaça paddocks under three rest periods over succeeding grazing cycles

\begin{tabular}{|c|c|c|c|}
\hline \multirow[t]{2}{*}{$\begin{array}{l}\text { Período de descanso } \\
\text { Restperiod }\end{array}$} & \multicolumn{3}{|c|}{$\begin{array}{l}\text { Ciclo de pastejo } \\
\text { Grazing cycle }\end{array}$} \\
\hline & $1^{\mathrm{o}}\left(1^{s t}\right)$ & $2^{\mathrm{o}}\left(2^{n d}\right)$ & $3^{\mathrm{o}}\left(3^{r d}\right)$ \\
\hline $\begin{array}{l}2,5 \text { folhas } \\
2,5 \text { leaves }\end{array}$ & $14,4 \mathrm{Ab}(269)$ & $16,2 \mathrm{ABb}(261)$ & $18,7 \mathrm{Aa}(351)$ \\
\hline $\begin{array}{l}3,5 \text { folhas } \\
3.5 \text { leaves }\end{array}$ & $15,5 \mathrm{Aa}(240)$ & $17,3 \mathrm{Aa}(300)$ & $15,2 \mathrm{Ba}(240)$ \\
\hline $\begin{array}{l}4,5 \text { folhas } \\
4.5 \text { leaves }\end{array}$ & $16,1 \mathrm{Aa}(259)$ & $15,3 \mathrm{Ba}(233)$ & - \\
\hline
\end{tabular}

Portanto, em relvado de azevém perene (Lolium perenne), na fase vegetativa, o perfilhamento diminuiu quando seu IAF se aproximou de 3,0 e cessou completamente sob IAF mais alto, quando praticamente toda a luz incidente foi interceptada (Simon \& Lemaire, 1987). De fato, o pastejo intenso condiciona o desenvolvimento de dossel baixo, com numerosos perfilhos de pequeno porte, enquanto o pastejo leniente propicia dossel alto, com grandes perfilhos, pouco numerosos (Nelson \& Zarrough, 1981; Sbrissia et al., 2001).

A biomassa de forragem verde total (pré-pastejo) reflete a interação período de descanso x ciclo de pastejo (Tabela 3), observando-se valores mais altos em piquetes sob maior período de descanso, diferença que se acentua com o suceder dos ciclos de pastejo, reflexo também do alongamento das hastes. Por outro lado, a biomassa de folhas permaneceu inalterada, de modo que os incrementos de biomassa total decorreram do acúmulo da fração hastes. Vale enfatizar que o estreitamento da relação folha/colmo do dossel tem efeito negativo sobre a eficiência de utilização da forragem produzida, agravando o pastejo seletivo dos animais (Carvalho et al., 2001).

A relação folha/colmo variou $(\mathrm{P}<0,05)$ inversamente com a duração do período de descanso (Tabela 4), repetindo os resultados de Santos et al. (1999), que estudaram a mesma cultivar sob pastejo intermitente e observaram desfolhação em intervalos de 28, 38 e 48 dias.

Refletindo o progressivo alongamento das hastes, a relação folha/colmo se estreitou $(\mathrm{P}<0,05)$ com a 
Tabela 3 - Massa seca de forragem verde pré-pastejo $(\mathrm{kg} / \mathrm{ha})$ em piquetes de Panicum maximum cv. Mombaça sob três períodos de descanso, ao longo de ciclos de pastejos sucessivos

Table 3 - Pre-grazing green herbage dry mass $(\mathrm{kg} / \mathrm{ha}$ ) in Panicum maximum cv. Mombaça paddocks under three rest periods over succeeding grazing cycles

\begin{tabular}{lccc}
\hline $\begin{array}{l}\text { Período de descanso } \\
\text { Rest period }\end{array}$ & \multicolumn{3}{c}{$\begin{array}{c}\text { Ciclo de pastejo } \\
\text { Grazing cycle }\end{array}$} \\
\cline { 2 - 4 } & $11^{\mathrm{o}}$ & $2^{\mathrm{o}}$ & $3^{\mathrm{o}}$ \\
\hline 2,5 folhas & $3609 \mathrm{Ab}$ & $3655 \mathrm{Ba}$ & $4447 \mathrm{Ba}$ \\
2.5 leaves & & & \\
3,5 folhas & $4987 \mathrm{Aa}$ & $6534 \mathrm{Aa}$ & $8013 \mathrm{Aa}$ \\
3.5 leaves & & & \\
4,5 folhas & $5659 \mathrm{Ab}$ & $8062 \mathrm{Aa}$ & - \\
4.5 leaves & & & \\
\hline
\end{tabular}

Médias seguidas por letras distintas, maiúsculas nas colunas e minúsculas nas linhas, diferem $(P<0,05)$ pelo teste Tukey.

Means by distintct capital and lower case letters in columns and line, respectively, differ $(P<, 05)$ by Tukey test.

Tabela 4 - Relação folha/colmo do dossel de Panicum maximum cv. Mombaça sob três períodos de descanso, ao longo de ciclos de pastejos sucessivos

Table 4 - Leaf/culm ratio of Panicum maximum cv. Mombaça canopy under three rest periods over succeeding grazing cycles

\begin{tabular}{lccc}
\hline $\begin{array}{l}\text { Período de descanso } \\
\text { Rest period }\end{array}$ & \multicolumn{3}{c}{$\begin{array}{c}\text { Ciclo de pastejo } \\
\text { Grazing cycle }\end{array}$} \\
\cline { 2 - 4 } & $1 \underline{\mathrm{o}}$ & $2 \mathrm{o}$ & $3 \underline{\mathrm{o}}$ \\
\hline 2,5 folhas & $2,93 \mathrm{Aa}$ & $2,15 \mathrm{Aab}$ & $1,87 \mathrm{Ab}$ \\
2.5 leaves & & & \\
3,5 folhas & $2,13 \mathrm{ABa}$ & $1,64 \mathrm{ABab}$ & $0,92 \mathrm{Ab}$ \\
3.5 leaves & & & \\
4,5 folhas & $1,91 \mathrm{Ba}$ & $1,26 \mathrm{Ba}$ & - \\
4.5 leaves & & & \\
\hline
\end{tabular}

Médias seguidas por letras distintas, maiúsculas nas colunas e minúsculas nas linhas, diferem $(P<0,05)$ pelo teste Tukey.

Means by distintct capital and lower case letters in columns and line, respectively, differ $(P<.05)$ by Tukey test.

sucessão dos ciclos de pastejo (Tabela 4). O controle do alongamento das hastes é um grande desafio a ser solucionado pelo manejo, que poderia ser alcançado com pastejos freqüentes e pesados. Porém, Uebele (2002) não conseguiu manter em $30 \mathrm{~cm}$ o resíduo do dossel do capim-mombaça sob pastejo de lotação intermitente, observando período de descanso relativamente longo, que permitia a quase completa interceptação da luz, resultante do pastejo seletivo praticado pelos novilhos e da sua baixa eficiência de pastejo num horizonte inferior àquele definido pela altura das hastes.

A altura do resíduo cresceu com o período de descanso $(\mathrm{P}<0,05)$, com tendência de aumento com o suceder dos ciclos de pastejo (Tabela 5), principalmente em piquetes sob longo período de descanso. Vale enfatizar sua relativa estabilidade em piquetes, observando o período de descanso mais curto, de 2,5 novas folhas expandidas por perfilho.
A biomassa de colmos e a relação folha/colmo do resíduo pós-pastejo encontram-se na Tabela 6; enquanto a relação folha/colmo se estreitou a biomassa de colmo cresceu com a duração do período de descanso, em razão do pastejo seletivo dos novilhos.

\section{Características morfogênicas}

Em piquetes manejados para serem desfolhados com 2,$5 ; 3,5$ e 4,5 novas folhas foram observados, respectivamente, períodos de descanso de 24 a 41, 35 a 52 e 44 a 63 dias, evidenciando a influência das condições de ambiente, principalmente pluviosidade (Figura 1), sobre a morfofisiologia da forrageira e, portanto, a precariedade de se preestabelecer a duração do período de descanso, segundo um número fixo de dias.

As taxas de alongamento de lâminas foliares e das hastes e de senescência de lâminas foliares, em 
Tabela 5 - Altura pós-pastejo (cm) do dossel de Panicum maximum cv. Mombaça, ao longo de ciclos de pastejos sucessivos dentro de cada período de descanso

Table 5 - Post-grazing canopy height $(\mathrm{cm})$ of Panicum maximum cv. Mombaça under three rest periods over succeeding grazing cycles

\begin{tabular}{lccc}
\hline $\begin{array}{l}\text { Período de descanso } \\
\text { Rest period }\end{array}$ & \multicolumn{3}{c}{$\begin{array}{c}\text { Ciclo de pastejo } \\
\text { Grazing cycle }\end{array}$} \\
\cline { 2 - 4 } & $1^{\mathrm{o}}\left(1^{\text {st }}\right)$ & $2^{\mathrm{o}}\left(2^{\text {nd }}\right)$ & $3^{\mathrm{o}}\left(3^{\text {rd }}\right)$ \\
\hline $\begin{array}{l}2,5 \text { folhas } \\
\text { 2.5 leaves }\end{array}$ & $38,2 \mathrm{Ba}$ & $39,3 \mathrm{Ba}$ & $39,4 \mathrm{Ba}$ \\
3,5 folhas & & & \\
3.5 leaves & $46,8 \mathrm{Aba}$ & $57,1 \mathrm{ABa}$ & $65,4 \mathrm{Aa}$ \\
$\begin{array}{l}4,5 \text { folhas } \\
\text { 4.5 leaves }\end{array}$ & $59,1 \mathrm{Aa}$ & $68,6 \mathrm{Aa}$ & - \\
\hline
\end{tabular}

Médias seguidas por letras distintas, maiúsculas nas colunas e minúsculas nas linhas, diferem $(P<0,05)$ pelo teste Tukey.

Means by distintct capital and lower case letters in columns and line, respectively, differ $(P<, 05)$ by Tukey test.

Tabela 6 - Relação folha/colmo e massa seca de colmo verde (MSCV) do resíduo pós-pastejo em piquetes de Panicum maximum cv. Mombaça sob três períodos de descanso, no último ciclo de pastejo

Table 6 - Leaf/culm ratio and green culm dry mass (GCDM) of the stubble in Panicum maximum cv. Mombaça paddocks under three rest periods on the last grazing cycle

\begin{tabular}{lcc}
\hline $\begin{array}{l}\text { Período de descanso } \\
\text { Rest period }\end{array}$ & $\begin{array}{c}\text { Relação folha/colmo } \\
\text { Leaf/culm ratio }\end{array}$ & $\begin{array}{c}\text { MSCV (kg/ha) } \\
(G C D M)\end{array}$ \\
\hline $\begin{array}{l}2,5 \text { folhas } \\
2.5 \text { leaves }\end{array}$ & $0,63^{\mathrm{a}}$ & $1817^{\mathrm{b}}$ \\
3,5 folhas & $0,57^{\mathrm{ab}}$ & $2839^{\mathrm{a}}$ \\
3.5 leaves & $0,43^{\mathrm{b}}$ & $3447^{\mathrm{a}}$ \\
4,5 folhas & leaves &
\end{tabular}

Médias na mesma coluna, seguidas de letras distintas, diferem $(P<0,05)$ pelo teste Tukey.

Means by distintct capital and lower case letters in columns and line, respectively, differ $(P<, 05)$ by Tukey test.

função do período de descanso e dos ciclos de pastejo, são apresentadas na Tabela 7.

Os períodos de descanso não tiveram efeito $(\mathrm{P}>0,05)$ sobre a taxa de alongamento foliar, cujos valores médios (Tabela 7) corroboram aqueles relatados por Gomide \& Gomide (2000), entre 6 e $8 \mathrm{~cm} /$ perfilho x dia, para a mesma cultivar. Diferentemente, a taxa de alongamento das hastes variou substancialmente conforme o período de descanso, com valores mais altos correspondendo aos piquetes sob período de descanso de 4,5 novas folhas. Este resultado é explicado pelo intenso e prolongado sombreamento mútuo dos perfilhos, com comprometimento da relação vermelho/vermelho extremo e, conseqüentemente, do perfilhamento e favorecimento do acúmulo de hastes (Chory, 1997; Davis \& Simmons, 1994; Deregibus et al., 1985). A taxa de alongamento das hastes também cresceu com o suceder dos ciclos de pastejo (Tabela 7), contribuindo para o acúmulo de resíduo pós-pastejo, evidenciado pela progressiva elevação da altura do dossel.

No presente estudo, o dossel dos piquetes sob período de descanso necessário para a expansão de 2,5 novas folhas alcançou IAF crítico com a entrada dos novilhos nos piquetes, mas aqueles manejados para se observar a expansão de 4,5 novas folhas permaneceram mais tempo, interceptando quase toda a radiação fotossinteticamente ativa (Cândido, 2003), à espera da introdução dos novilhos nos piquetes.

Diferentemente, a taxa de senescência foliar (Tabela 7) não respondeu ( $\mathrm{P}>0,05)$ aos períodos de descanso, contrariando dos relatos de Korte et al. (1984). Segundo Korte et al. (1982), a senescência de folhas se intensifica após o dossel alcançar seu IAF crítico, em que ocorre intercepção de $95 \%$ da radiação luminosa incidente.

A taxa de senescência foliar decresceu $(\mathrm{P}<0,05)$ do primeiro para o terceiro ciclo de pastejo, o que se 
atribui à mais alta pluviosidade ocorrida nos primeiros meses do ensaio, acelerando o fluxo de biomassa. Segundo Mattos (2001), a senescência foliar de diferentes espécies de Brachiaria se intensifica sob condições de alagamento. Além disso, o progressivo alongamento das hastes, com o suceder dos ciclos de pastejo, contribuiria para reduzir a senescência foliar (Tabela 7).

O acúmulo de forragem (Tabela 8), estimado a partir destes índices morfogênicos e da densidade populacional de perfilhos, variou com o período de descanso $(\mathrm{P}<0,05)$. Valores mais baixos foram observados em piquetes sob período de descanso de 3,5 novas folhas, mas não variaram com os ciclos de pastejo.
Refletindo o alto potencial forrageiro do capimmombaça, a taxa de acúmulo de forragem variou de 93 a $202 \mathrm{~kg} / \mathrm{ha}$ x dia conforme o período de descanso do piquete, com média de $148 \mathrm{~kg} / \mathrm{ha}$ x dia, próxima daquela relatada por Quadros et al. (2002), para a mesma cultivar recebendo dose equivalente de adubação nitrogenada.

A mais alta taxa de acúmulo de forragem observada nos piquetes sob período de descanso de 2,5 novas folhas foi resultante da elevada taxa de alongamento foliar e densidade populacional de perfilhos, enquanto a alta taxa de acúmulo de forragem em piquetes com períodos de descanso de 4,5 novas folhas foi, em grande parte, resultado da elevada taxa de alongamento das hastes.

Tabela 7 - Taxa de alongamento de folhas (TAIF) e das hastes (TAIH) e de senescência foliar (TSF) em perfilhos de Panicum maximum cv. Mombaça sob três períodos de descanso, ao longo de ciclos de pastejo sucessivos

Table 7 - Leaf (LER) and culm (CER) elongation rates and leaf senescence rate (LSR) of Panicum maximum CV. Mombaça under three rest periods over succeeding grazing cycles

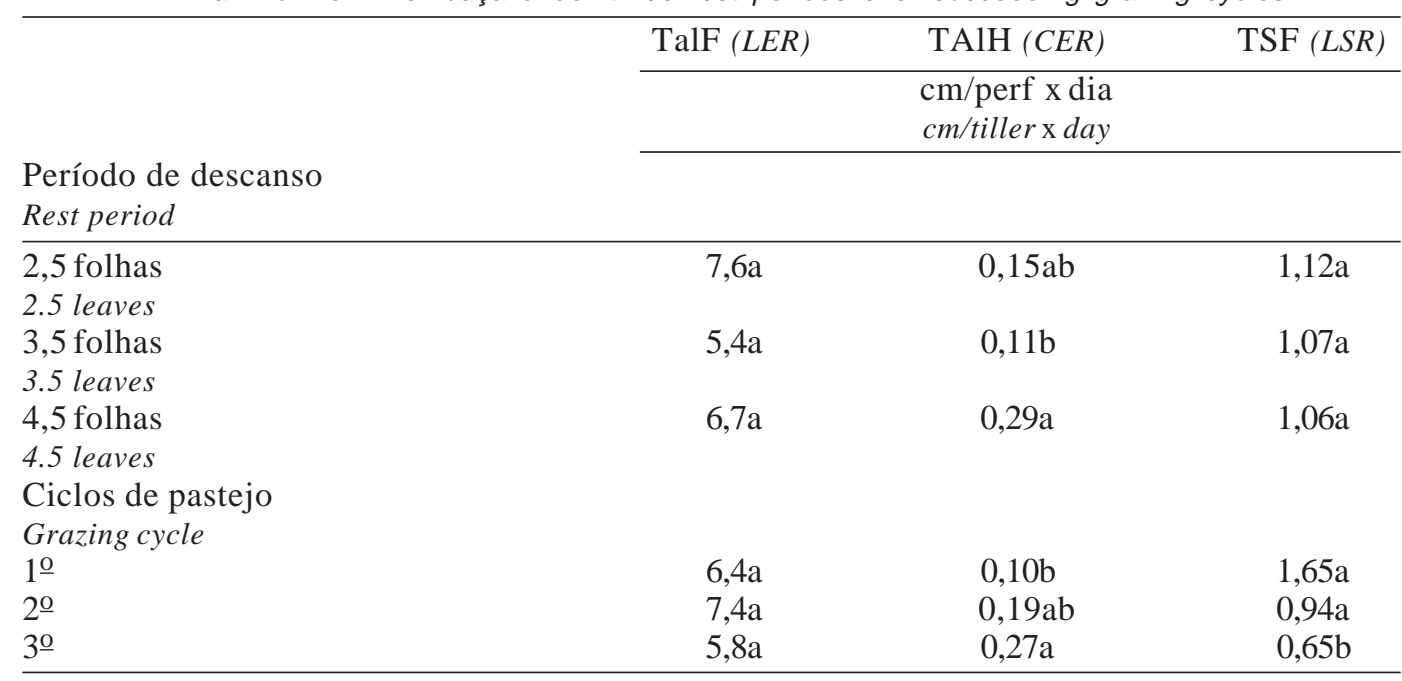

Médias na mesma coluna, seguidas de letras distintas, diferem $(P<0,05)$ pelo teste Tukey.

Means by distintct capital and lower case letters in columns and line, respectively, differ $(P<.05)$ by Tukey test.

Tabela 8 - Taxa de acúmulo de massa seca de forragem (TAF) estimada a partir das características morfogênicas de dossel de Panicum maximum cv. Mombaça sob três períodos de descanso, ao longo de ciclos de pastejo sucessivos

Table 8 - Net herbage dry mass accumulation rate (NHAR) estimated from morphogenetic traits of Panicum maximum cv. Mombaça canopy under three rest periods and over succeeding grazing cycles

\begin{tabular}{lccc}
\hline $\begin{array}{l}\text { Período de descanso } \\
\text { Rest period }\end{array}$ & $\begin{array}{c}\text { TAF }(\mathrm{kg} / \mathrm{hax} \mathrm{d}) \\
\text { NHAR }\end{array}$ & $\begin{array}{c}\text { Ciclo de pastejo } \\
\text { Grazing cycle }\end{array}$ & $\begin{array}{c}\mathrm{TAF}(\mathrm{kg} / \mathrm{hax} \mathrm{d}) \\
\text { NHAR }\end{array}$ \\
\hline 2,5 folhas (2.5 leaves) & $202^{\mathrm{a}}$ & $1 \underline{\mathrm{o}}$ & $121^{\mathrm{a}}$ \\
3,5 folhas (3.5 leaves) & $93 \mathrm{~b}$ & $2^{\mathrm{o}}$ & $181^{\mathrm{a}}$ \\
4,5 folhas (4.5 leaves) & $149^{\mathrm{a}}$ & $3^{\mathrm{o}}$ & $142^{\mathrm{a}}$
\end{tabular}

Médias na mesma coluna, seguidas de letras distintas, diferem $(P<0,05)$ pelo teste Tukey.

Means by distintct capital and lower case letters in columns and line, respectively, differ $(P<.05)$ by Tukey test. 


\section{Conclusões}

As características morfogênicas e estruturais variaram em resposta aos períodos de descanso, sendo as maiores respostas verificadas nas variáveis relacionadas ao processo de alongamento de colmos, como a taxa de alongamento das hastes e a relação folha/colmo.

O período de descanso mais curto, correspondente à expansão de 2,5 novas folhas, foi o único a exercer algum controle sobre o alongamento das hastes, com o suceder dos ciclos de pastejo.

O prolongamento do período de descanso propiciou, com o decorrer dos ciclos de pastejo, o desenvolvimento de dossel mais alto e maior biomassa de forragem verde, no início do período de pastejo, porém com proporção crescente de colmos, acarretando acentuado comprometimento da relação folha/colmo.

\section{Literatura Citada}

BROUGHAM, R. W. Effect of intensity of defoliation on regrowth of pasture. Australian Journal of Agricultural Research, v.7, p.377-387, 1956.

CARVALHO, P.C.F.; MARÇAL, G.K.; RIBEIRO FILHO, H.M.N. et al. Pastagens altas podem limitar o consumo dos animais. In: REUNIÃO DA SOCIEDADE BRASILEIRA DE ZOOTECNIA, 38., 2001, Piracicaba. Anais... Piracicaba: Sociedade Brasileira de Zootecnia, 2001. (cd-rom)

CHORY, J. Light modulation of vegetative development. The Plant Cell, v.9, p.1225-1234, 1997.

DAVIES, A. Tissue turnover in the sward. In: DAVIES, A. et al. (Eds.). Sward measurement handbook. 2.ed. Reading: British Grassland Society, 1993. p.183-216.

DAVIS, M.H.; SIMMONS, S.R. Far-red light reflected from neighbouring vegetation promotes shoot elongation and accelerates flowering in spring barley plants. Plant, Cell and Environment, v.17, p.829-836, 1994.

DEREGIBUS, V.A.; SANCHEZ, R.A.; CASAL, J.J. et al. Tillering response to enrichment of red light beneath the canopy in a humid natural grassland. Journal of Applied Ecology, v. 22, p. 199-206, 1985.

FULKERSON, W. J.; DONAGHY, D.J. Plant soluble carbohydrate reserves and senescence - key criteria for developing an effective grazing management system for ryegrass based pasture: a review. Australian Journal Experimental Agriculture, v. 41, p.261-275, 2001.

GOMIDE, C.A.M.; GOMIDE, J.A. Morfogênese de cultivares de Panicum maximum Jacq. Revista Brasileira de Zootecnia, v.29, p.341-348, 2000.

GRANT, S.A.; BARTHRAM, G.T.; TORVELL, L. et al. Comparison of herbage production under continuous stocking and intermittent grazing. Grass and Forage Science, v.43, p.29-39, 1988.
KORTE, C.J.; WATKIN, B.R.; HARRIS, W. Use of residual leaf area index and light interception as criteria for spring-grazing management of ryegrass dominant pasture. New Zealand Journal of Agricultural Research, v.25, p.309-319, 1982.

KORTE, C.J.; WATKIN, B.R.; HARRIS, W. Effects of the timing and intensity of spring-grazings on reproductive development, tillering, and herbage production of perennial ryegrass dominant pasture. New Zealand Journal of Agricultural Research, v.27, p.135-149, 1984.

LEMAIRE, G.; CHAPMAN, D. Tissue flows in grazed plant communities. In: HODGSON, J.; ILLIUS, A.W. (Eds.) The ecology and management of grazing systems. Wallingford: CAB International, 1996. p.3-36.

MATTOS, J.L.S. Avaliações morfofisiológicas de espécies de Brachiaria sob diferentes disponibilidades de água no solo. Viçosa, MG: Universidade Federal de Viçosa, 2001. 122p. Tese (Doutorado em Zootecnia) - Universidade Federal de Viçosa, 2001.

NELSON, C.J.; ZARROUGH, K.M. Tiller density and tiller weight as yield determinants of vegetative swards. In: OCCASIONAL SYMPOSIUM - PLANT PHYSIOLOGY AND HERBAGE PRODUCTION, 13., 1981, England. Proceedings... England: British Grassland Society, 1981. p.25-29.

OLIVEIRA, M.A.; PEREIRA, O.G.; MARTINEZ Y HUAMAN, C.A. et al. Características morfogênicas e estruturais do capim-Bermuda 'Tifton 85' (Cynodon spp.) em diferentes idades de rebrota. Revista Brasileira de Zootecnia, v.29, p.1939-1948, 2000 (supl.1).

PARSONS, A.J.; PENNING, P.D. The effect of duration of regrowth on photosynthesis, leaf death and the average rate of growth in a rotationally grazed sward. Grass and Forage Science, v.43, p.15-27, 1988.

PARSONS, A.J.; LEAFE, E.L.; COLLETT, B. et al. The physiology of grass production under grazing. II Photosynthesis, crop growth and animal intake of continuously grazed sward. Journal of Applied Ecology, v.20, n. 1, p.127139, 1983.

PEDREIRA, J.V.S.; BOIN, C. Estudo de crescimento do capim elefante, variedade napier (Pennisetum purpureum Schum.). Boletim de Indústria animal, v.26, n.s., p.263-273, 1969. QUADROS, D.G.; RODRIGUES, L.R.A.; FAVORETTO, V. et al. Componentes da produção de forragem em pastagens dos capins Tanzânia e Mombaça adubadas com quatro doses de NPK. Revista Brasileira de Zootecnia, v.31, p.1333-1342, 2002 (supl.).

ROBSON, M.J. The growth and development of simulated swards of perennial ryegrass. I. Leaf growth and dry weight change as related to the ceiling yield of a seedling sward. Annals of Botany, v.37, p.487-500, 1973.

SANTOS, P.M.; CORSI, M.; BALSALOBRE, M.A.A. Efeito da freqüência de pastejo e da época do ano sobre a produção e a qualidade em Panicum maximum cvs. Tanzânia e Mombaça. Revista Brasileira de Zootecnia, v.28, p.244-249, 1999.

STATISTICAL ANALYSES SYSTEM - SAS. SAS system for windows. Version 8.0. Cary: 1999. 2 CD-ROMs. 
SBRISSIA, A.F.; SILVA, S.C.; CARVALHO, C.A.B. et al. Tiller size/population density compensation in grazed coastcross bermudagrass swards. Scientia Agricola, v.58, p.655-665, 2001.

SIMON, J.C.; LEMAIRE, G. Tillering and leaf area index in grasses in the vegetative phase. Grass and Forage Science, v.42, p.373-380, 1987.

SMITH, H. Light quality, photoperception and plant strategy. Annual Review of Plant Physiology, v.33, p.481-518, 1982.

UEBELE, M.C. Padrões demográficos de perfilhamento e produção de forragem em pastos de capim-mombaça submetidos a regimes de lotação intermitente. Piracicaba: Escola Superior de Agricultura Luiz de Queiroz, 2002. 83p. Dissertação (Mestrado em Agronomia) - Escola Superior de Agricultura Luiz de Queiroz, 2002.
WAN, C.; SOSEBEE, R.E. Tillering responses to red - far red light ratio during different phenological stages in Eragrostis curvula. Environmental and Experimental Botany, v.40, p.247-254, 1998.

Recebido em: 11/02/04

Aceito em: 24/01/05 